\title{
Estratégia didática clássica aplicada à disciplina Geologia Introdutória do curso de Geologia da Universidade Federal da Bahia*
}

\author{
Osmário Rezende Leite \\ Departamento de Geologia e Geofísica Aplicada \\ osmariol@ufba.br \\ Paulo Eduardo Avanzo \\ Departamento de Sedimentologia \\ Joil José Celino \\ Departamento de Geologia e Geofísica Aplicada \\ Instituto de Geociências - Universidade Federal da Bahia (UFBa) \\ joil@ufba.br
}

\footnotetext{
*Este documento deve ser referido como segue:
}

Leite 0.R., Avanzo P.E., Celino J.J. 2007. Estratégia didática clássica aplicada à disciplina Geologia Introdutória do curso de geologia da Universidade Federal da Bahia. Terræ Didatica, 4(1): 04-13.

$<$ http://www.ige.unicamp.br/ terraedidatica/>

\begin{abstract}
Classic didactic strategy applied to the Introductory Geology in the course of geology from the Federal University of Bahia. It is well-known that the schools create a separated world of daily life, then pupils accustom early to different positions in each one of these circumstances. Teachers go to the classroom with a program, a changeable textbook, some resources that to a large extent summarize transparencies or the chalk and black picture, and a number of questions for examinations. The teachers act inside classrooms in accordance with custom rules, against the common-sense they use outside. As soon as they notice any reduction of progress, they are capable to calmly follow the same routine lessons even if faced by evidence that pupils demonstrate lack of progress in evaluations. This work is centered on practical readjustments in education method and in a short-term didactic strategy with intention to adjust and to adapt the course to deal with the problems detected during the learning period of the Introductory Geology disciplines at the Geology undergraduate course of the Federal University of Bahia.
\end{abstract}

KEYWORDS Geology teaching, didactic strategies, geology.

RESUMO É notório que as escolas criam um mundo apartado da vida cotidiana e, logo cedo os alunos se acostumam a posturas diferentes em cada uma dessas circunstâncias. O professor adentra a sala de aula, munido de um programa, um livro texto, alguns recursos variáveis que em grande parte se resumem a transparências ou a giz e quadro negro, e uma bagagem de questões para as provas. Os professores agem bem mais de acordo com preceitos de praxe dentro das salas, do que com o bom senso que utilizam fora delas. Assim que constatam qualquer falta de rendimento, também são capazes de seguir rotineira e tranqüilamente com suas aulas, mesmo constatando que nas avaliações os alunos demonstram falta de rendimento. Neste trabalho reflete-se sobre o objetivo prático de reajustamentos no método de ensino e na estratégia didática a curto prazo com o intuito de adequar e adaptar o curso frente a problemas detectados durante o período letivo da disciplina Geologia Introdutória do curso de Geologia da Universidade Federal da Bahia.

PALAVRAS CHAVE Ensino de Geologia, estratégias didáticas, geologia. 


\section{Introdução}

É notório que as escolas criam um mundo apartado da vida cotidiana e logo cedo os alunos se acostumam a posturas diferentes em cada uma dessas circunstâncias. Os professores agem bem mais de acordo com preceitos de praxe dentro das salas, do que com o bom senso que utilizam fora delas (Villani \& Pacca 1998). Em outras palavras, enquanto são capazes de levar seus carros à oficina, assim que constatam qualquer falta de rendimento, também são capazes de seguir rotineira e tranqüilamente com suas aulas mesmo constatando que nas avaliações os alunos demonstram falta de rendimento!

Por que o professor não pára o curso para proceder a reparos técnicos, assim como faz com seu carro?

Porque aula é aula, vida é vida. Existe o conteúdo programático a ser cumprido, a carga horária estrita (ou restrita) e exigências formais que dificultam, é certo.

Para Perrenoud (1999), proceder a reparos técnicos na aula não seria uma tarefa fácil, visto que não há quase nada pronto no campo da avaliação formativa. Dizia o autor ser necessário reinventá-la, criar mecanismos de regulação didática e aliá-la à intuição e à instrumentação. Para isso o autor lança o seguinte desafio:

Não basta ser adepto da idéia de uma avaliação formativa. Um professor deve ainda ter os meios de construir seu próprio sistema de observação, interpretação e intervenção em função de sua concepção pessoal de ensino, dos objetivos, do contrato didático, do trabalho escolar. Propor modelos de ação que exigiriam do agente a renúncia ao que ele é, ao que ele faz de boa vontade, ao que ele crê justo ou eficaz não pode levar a uma mudança duradoura das práticas.

Com preceitos de praxe, o professor adentra a sala de aula, munido de um programa, um livro texto, alguns recursos variáveis que em grande parte se resumem a transparências ou a giz e quadro negro, e uma bagagem de questões para as "provas". Ainda que, em geral, o próprio professor não se dê conta, acontece que tudo isso vem sustentado por uma filosofia de trabalho, uma postura axial de relacionamento com os alunos, uma escolha metodológica e, conseqüentemente, uma estratégia didática que é utilizada durante o curso (Cunha 1995). A maioria esmagadora dos docentes age como age porque consideram seu procedimento como o único correto existente, e mais nenhum outro.

Os professores-autores depois de muitas discussões preliminares iniciaram um trabalho conjunto, em 1994, embora a Geologia Introdutória nesta época se dividisse em duas disciplinas semestrais (Geologia Geral I e Geologia Geral II). Mas o trabalho era sempre bem entrosado, o professor da I participava das aulas da II e vice-versa. O principal motivo desta união foi a intenção de fazer frente à evasão que se revelava muito alta desde quase dez anos antes.

O objetivo prático de reajustamentos na estratégia didática a curto prazo é adequar e adaptar o curso frente a problemas detectados durante o próprio período letivo da disciplina Geologia Introdutória (GEO 039) do Instituto de Geociências (IGEO) da Universidade Federal da Bahia (UFBA). Portanto é um objetivo que se esgota ao final de cada ano e se recoloca no início de cada nova turma.

Quanto aos objetivos a longo prazo nosso intento é:

a) colecionar uma série de atividades de sala de aula em todas as suas possíveis versões, segundo cada estratégia didática; e

b) relacionar todos os parâmetros de referência que permitam, a qualquer outro professor, decidir por esta ou aquela versão de uma mesma atividade, baseado no diagnóstico da situação da turma de estudantes.

\section{Um histórico de descobertas}

Os métodos de ensino são instrumentos que se colocam à disposição do professor para a efetivação do processo de ensino, representam o "fazer didático" (Nérici 1981). Ao longo destes anos, os autores pesquisaram formas de ensino que mais se adaptaram aos seus alunos, aproveitando quando viável parte dos métodos conhecidos, procurando estruturar novas formas de ensino mais ajustadas à realidade pedagógica que tinham que enfrentar.

Logo, os métodos de ensino aplicados e agora apresentados são meras sugestões que podem e devem ser modificadas, com base na experiência e reflexão, visando unicamente à melhor formação do educando e maior eficiência no ensino.

Um dos autores iniciou seu trabalho no IGEO, experimentando um método novíssimo na época (1973), o método Keller, de más lembranças. Alterando a metodologia, passou por 
dificuldades até que percebeu que o Método Germinal (ou "método das tarefas") era o mais produtivo, pois os alunos conseguiam compor relatórios e perfis geológicos nos trabalhos de campo, inteiramente por conta própria. No entanto, na década de 80 , esta nova opção já não trazia resultados satisfatórios, e o método mais promissor foi o Monográfico, onde os alunos conseguiam compor monografias simples, mas interessantes e, às vezes, inéditas. Durante este tempo, tal professor era solicitado pela Universidade de Campinas (Unicamp) para auxiliar em cursos de especialização e participar de seminários sobre ensino nas Geociências, e publicou vários artigos técnicos sobre ensino.

O método Keller também denominado por PSI (Personalized System of Instruction) foi criado em 1963, pelo professor Fred Keller e tornou-se bastante popular na década de 1970. De 1973 a 1979, manteve-se em funcionamento no Center for Personalized Instruction na Georgetown University (Moreira 2007).

No PSI, aulas expositivas e demonstrações têm papel motivacional, em vez de fonte de informações para o desenvolvimento da disciplina. Cada aluno recebe seu próprio material (manuais, resumos, texto, exercícios etc.), e é instruído sobre como conduzir seus estudos, não havendo necessidade de aula para transmissão do conhecimento. É comum, no PSI, que o aluno participe de uma aula somente após compreender o conteúdo que será tratado naquela aula.

Entende-se, no entanto, que o professor pode, de acordo com as peculiaridades da disciplina, fazer as adaptações necessárias a qualquer das etapas do método Keller, sem que este seja descaracterizado (Bulhões 2007).

O Método das Tarefas (Nérici 1981) consiste na complementação da apresentação do professor por meio de tarefas dirigidas e discussão dos dados assim obtidos. O professor apresenta um tema ou uma unidade, principalmente com finalidade motivadora e de pequena extensão para execução de tarefas por parte dos educandos. O professor terá o trabalho de preparar tarefas bem planejadas, com indicações precisas, tipo "folhas de serviço", que devem ser bastante explícitas, de maneira a descer a detalhes que orientem adequadamente o educando. Um tema ou unidade apresentado pelo professor pode ser seguido por mais de uma tarefa dirigida, dada uma após a outra, em ordem desejada, bem como o grau de perfeição de uma habilidade quando for o caso.

As tarefas dirigidas podem ser levadas a efeito durante os períodos de aula ou não, individualmente ou em grupo.

O Método Monográfico ou método da pesquisa (Nérici 1981) consiste em levar o educando a observar, recolher dados, e refletir sobre eles. Esses dados podem provir de manifestações espontâneas ou provocadas, da natureza, da sociedade ou do homem.

O Método expositivo (Nérici 1981) consiste na apresentação oral de um tema logicamente estruturado. O recurso principal da exposição é a linguagem oral, que deve merecer o máximo cuidado por parte do expositor. A exposição pode assumir duas posições didáticas:

a) exposição dogmática, em que a mensagem transmitida não pode ser contestada, devendo ser aceita sem discussões e com a obrigação de repeti-la, por ocasião das formas de verificação.

b) exposição aberta, em que a mensagem apresentada pelo professor é simples pretexto para desencadear a participação da classe, podendo haver, assim, contestação, pesquisa e discussão sempre que oportuno e necessário. É neste sentido que hoje se entende o método expositivo nos domínios da educação.

Após esta rápida explicação sobre os métodos faremos uma rápida retrospectiva dos antecedentes do nosso atual trabalho, para uma melhor compreensão do leitor.

O segundo autor participou de um desses cursos de especialização em Ensino de Geociências na Unicamp em 1992 e desde então tem se esforçado em melhorar seu curso, e tem participado de discussões e mesas-redondas sobre ensino. O terceiro autor iniciou sua carreira como professor da Escola Técnica Federal da Bahia (atual CEFET-Ba), passando para a UFBa em 1992, e também participou do Curso de Especialização da Unicamp em 1994. No conjunto destas vivências em sala de aula, colecionaram-se várias descobertas:

a) Cada aluno tende a uma seqüência própria de aprendizado de Geologia Geral; portanto, o ordenamento dos tópicos de seu programa não 
deve ser rígido e imutável, por mais didático que pareça.

b) A aprendizagem de qualquer assunto, em especial de Geologia, atravessa obrigatoriamente uma fase inicial sincrética que deve ser assumida e trabalhada na sua obscuridade e confusão; caso contrário a aprendizagem continuará camuflada de forma confusa e obscura.

c) Quando o aluno é despertado para a exploração crítica de cada tema, as atividades de raciocínio geológico se tornam agradáveis e provocam seu interesse, bem o oposto da indiferença costumeira de se contentar com a primeira resposta que surja.

d) Uma atitude permanentemente aberta à avaliação do curso, sempre que necessário, é bastante eficiente, pois o tempo gasto é recuperável pela melhor produção do aluno, notadamente nos trabalhos de campo.

e) O aluno necessita de uma revaloração e reforço de si mesmo como ser útil e capaz de descobertas e criações, principalmente nas situações de campo, para conseguir sair do comodismo e da dependência a que foi condicionado pelo ensino tradicional.

f) O estudo de um conceito geológico é bem mais produtivo e marcante quando se parte da necessidade de aplicação direta numa situação prática, do que uma assimilação enciclopédica de informações como preparação para situações futuras que virão não se sabe quando. O que, no geral, acontece é que estas informações são esquecidas antes que surja a ocasião de aplicálas;

g) Os tópicos de Geologia Geral podem ser integrados em temas aglutinadores que permitem economia de esforços e de tempo; esses temas dependem do interesse peculiar de cada turma e por isso devem ser decididos e planejados através do aluno.

Em 1997, por conta de um Projeto que buscava definir o perfil de Geólogo 2000, o trabalho mudou em vários aspectos: a disciplina se tornou anual, passou a se chamar Geologia Introdutória, deveria contar com uma equipe de especialistas, cada qual em sua área específica envolvida pela disciplina, o programa foi unificado, e mais alguns detalhes.

Da primeira experiência (com a turma de 1997) foram levantados os seguintes aspectos: os alunos passaram a se queixar do caráter anual e da troca periódica de professores; a maioria dos especialistas se desligou da equipe (restaram apenas os dois professores iniciais, sendo que um destes participou durante apenas uma semana); o programa da disciplina se caracterizou como sobrecarregado; a falta de um livro-texto de confiança não permitia ao alunado maiores orientações aos seus estudos, obrigando-os a se esmerarem nas anotações de aulas.

A falta de maior embasamento - a cada ano pior - dos alunos recém-ingressos criava uma enorme discrepância entre o nível exigido pela disciplina e o nível que os estudantes conseguiam acompanhar. Esta condição desemboca numa outra conseqüência mais séria que é a necessidade de, a partir de uma desinformação total do que seja a ciência geológica, criar um lastro mínimo de motivação no qual o aluno poderá ganhar impulso suficiente para levar o curso até o fim.

Além disso, ressalta-se a existência de problemas de infra-estrutura (as tradicionais aulas de bússola, no campo, carecem de bússolas; faltam recursos para a reprodução de textos, tais como papel e tinta para impressão em computador, dotações orçamentárias para xerox etc.) e da concorrência desigual imposta pelas chamadas "matérias externas" (Física e Matemática), notadamente por ocasião de suas respectivas provas escritas.

Com o intuito de fazer frente a esses problemas, embora eles não fossem propriamente de responsabilidade dos professores da disciplina, alguns reajustes foram promovidos, tais como:

a) O desligamento dos quatro especialistas foi compensado pelo revezamento dos professores que permaneceram e, na medida do possível, outros especialistas eram convidados para algumas aulas específicas.

b) O programa sobrecarregado foi reavaliado e iniciou-se uma sistemática solicitação de mudanças e reajustes.

c) A falta de um livro-texto confiável começou a ser remediada por uma coletânea de textos 
selecionados distribuídos aos alunos, e orientações para leitura de capítulos específicos de alguns livros.

d) A falta de embasamento dos estudantes foi e continua sendo minimizada por um verdadeiro "corpo-a-corpo" entre professores e alunos, onde as dúvidas mais cruciais são diagnosticadas e combatidas. Além disso, em 1999, foi criada, paralelamente, uma atividade de extensão visando um esforço de divulgação das ciências geológicas no $1^{\circ}$ e $2^{\circ}$ Graus de ensino, sob o título geral de "Geologia à Beira da Praia”, com a finalidade de atacar o problema em seu próprio nascedouro.

e) A necessidade de um lastro mínimo de motivação para o aluno tem sido atendida através da conscientização do papel da Geologia perante a sociedade, notadamente nas excursões de campo, cujo numero é o maior possível dentro das condições existentes.

Os problemas de infra-estrutura, por enquanto, vêm contando contribuições do próprio bolso dos professores (no caso dos textos, por exemplo) ou, por sumários cancelamentos de atividades (no caso das bússolas, por exemplo), seguido das respectivas notificações oficiais ao órgão competente.

a) A concorrência desigual das "disciplinas externas" detonou uma verdadeira campanha junto ao Colegiado do Curso de Graduação em Geologia, e junto aos próprios estudantes, no sentido de se encontrar uma solução razoável (seja qual for).

A postura em sala, sempre que os reajustes eram muito diferentes do normal, era consultar qual a disposição dos alunos de enfrentar a nova situação, e caso contrário utilizava-se o Método Expositivo sem nenhum problema. Ressalte-se que constantemente foi permitido aos alunos rever suas decisões e se por acaso percebessem que tinham se equivocado, em qualquer momento do curso, poderiam solicitar mudanças e eram atendidos. Entretanto o que aconteceu muitas vezes é que os professores percebiam antes dos alunos que as novas tentativas não estavam funcionando, e então, os próprios professores propunham as alterações cabíveis.

Em meados de 1997, os dois professores da dis- ciplina se deram conta que estavam realizando uma verdadeira pesquisa, pois estavam constantemente colhendo dados e observações, estavam refletindo detalhadamente sobre suas constatações e estavam reajustando a todo instante a maneira de ministrar o curso. Daí surgiu o projeto "Utilização do feed back das aulas para reajustes imediatos na estratégia didática da disciplina Geologia Introdutória do IGEO" que já produziu um relatório preliminar, aprovado nas reuniões especificas dos departamentos do IGEO envolvidos.

Em 1999, conseguimos finalmente fazer valer nossa solicitação de separação entre calouros e repetentes, com o ingresso de mais um professor, que ficou encarregado da turma dos repetentes. Com esta providência conseguiu-se aumentar o índice de aprovação. Ainda em 1999 surgiu o Grupo de Trabalho sobre a Matéria Geologia Geral, presidida pelo Diretor do IGEO, no qual a disciplina Geologia Introdutória também se encaixa. Neste grupo, conseguimos finalmente discutir o programa da disciplina e a partir de 2000 ele foi simplificado e tornou-se bem mais exeqüível.

\section{Fundamentação conceitual}

O conceito de pesquisa-ação é largamente utilizado em ciências sociais e envolve os contextos em que o próprio pesquisador participa como componente natural do caso em estudo. Ele não se coloca como um observador externo e descomprometido, e sim, como um dos elementos de influência no desenvolver de cada etapa.

No nosso caso, os executores da pesquisa são exatamente os professores responsáveis pela disciplina Geologia Introdutória que, ao mesmo tempo em que ministram suas aulas, observam, colhem dados, tiram conclusões, decidem por novas estratégias, promovem as modificações, controlam os resultados, reelaboram as concepções teóricas básicas e, enfim, produzem os relatórios técnicos sobre a real consecução dos objetivos.

A descoberta mais pitoresca foi quanto à metodologia. Nosso trabalho, em essência, perseguia o mito do "melhor método de ensino", até que nos demos conta de que esta busca é interminável, como a perseguição da linha do horizonte, sem nunca atingi-la por mais que nos aproximássemos dela. A cada ano surgia uma nova idéia metodológica, ou se tinha notícia da divulgação de alguma 
outra, de modo que sempre havia algo mais a ser testado. Além disso, a metodologia que obtinha sucesso num ano, não obrigatoriamente repetia o mesmo sucesso no ano seguinte, por mais que insistíssemos. Cada turma de alunos se revela com suas idiossincrasias específicas e sempre foi imprescindível uma grande dose de sensibilidade para diagnosticar as necessidades dos estudantes antes de optar pela melhor alternativa no caso. Portanto, concluímos que o tal "melhor método" não existe; existe sim, um leque de métodos, cada qual com suas virtudes e limites, que devem ser cuidadosamente pesados no momento de se decidir por qual utilizar.

Por isso nossa investigação atual não se dirige propriamente à "metodologia", mas a uma outra contingência, hierarquicamente menor, que se constitui na Estratégia Didática.

A metodologia didática procura apresentar estruturações de passos de atividades didáticas que orientem adequadamente a aprendizagem do educando. Segundo, as circunstâncias e o nível de maturidade do educando podem apresentar estruturas preponderantemente lógicas ou psicológicas (Nérici 1981).

Antes de algo mais, é interessante dar uma passada de olhos nas noções de método, estratégia didática e de técnica.

Método é derivado das palavras gregas "meta" (que se traduz como "ao longo de") e "hodos" (que significa "caminho"). Seria, portanto todo o encaminhamento de uma determinada ação. Não há espaço aqui para um ensaio sobre as definições de método e todas as suas controvérsias, mas pode-se tratar de sua conceituação. O conceito de método adotado neste trabalho é assim resumido: "Método é todo o conjunto estruturado de providências adequadas que consegue partir de um conteúdo válido e chegar a um outro conteúdo, totalmente distinto, mas igualmente válido" vinculado à visão de mundo, educação e sociedade. Ele é aplicável tanto em situações pedagógicas como nas próprias investigações científicas, permitindo em questões de ensino selecionar as providências adequadas e definir o conteúdo válido para além dos critérios básicos da área de conhecimento, mas tendo em vista os objetivos educacionais. Por "providências adequadas" entendem-se aquelas que seguem fielmente os princípios e as leis teóricas, obedecidas pelo método, e por "conteúdo válido" aquele que observa os critérios básicos da área de conhecimento a que pertence (um conteúdo científico deve satisfazer os critérios científicos). A técnica de ensino é o recurso particular de que se vale o professor para a efetivação dos propósitos do método.

A filosofia de trabalho fornece os princípios gerais da atividade didática e tudo deriva dela. É difícil mudar uma filosofia de trabalho, porém o professor deve estar aberto a esta possibilidade tendo em mãos, relacionadas e definidas, todas as opções filosóficas que considera aceitáveis e que julga coadunadas com sua personalidade e sua maneira de ser.

O reajuste de um curso pode ser feito com a alteração da estratégia didática em si, apenas; porém, se a situação exigir, é precedida por alteração no método de ensino, ou também ainda no relacionamento com os alunos, ou ainda mais até na filosofia de trabalho.

O relacionamento com os alunos é orientado por um eixo de conduta básica que deve estar bem claro e definido para os próprios docentes, para que também fique definido e claro para os estudantes. As possibilidades vão desde o extremo da dominação total (ou submissão total) do professor até o outro extremo da gestão plural (equivalente), dependendo do que se pretenda atingir. No geral, utilizam-se "meios-termos" entre estes dois extremos, marcadamente mais próximos da dominação do professor. As reformulações podem se dar mais para cá ou mais para lá conforme os problemas que emergem, norteadas pela filosofia de trabalho.

Estratégia didática é o conjunto de diretrizes práticas que norteiam as atividades de um curso, no permeio entre a metodologia da ciência particular, em foco, e a própria metodologia de ensino, que dirige o ministério desta ciência, envolvendo desde a escolha do tipo de "abordagem" da disciplina, passando pelo "mecanismo de tratamento do conteúdo", pelas "interligações dos temas principais" até "técnicas pedagógicas" específicas de cada momento.

Então, enquanto o método trata de todas as contingências envolvidas no contexto da ação, a estratégia se limita ao encadeamento de tópicos axiais que criam uma espécie de rotina de trabalho seguindo a metodologia própria da ciência em foco.

A técnica, facilmente confundida com o método, foi considerada aqui como o nível mais reduzido dentro da hierarquia metodológica. Ela deve atender às diretrizes de todas as outras hierarquias $\mathrm{e}$, mais diretamente, às diretrizes da estratégia 
adotada. Entende-se por técnica "o roteiro de procedimentos específicos que traz a maior eficiência possível na obtenção dos resultados definidos pelos objetivos do trabalho".

Para fazer frente a estas contingências, os professores poderão construir (ou reconstruir) cada reformulação necessária, o que exige uma boa dose de imaginação e criatividade, aliada a um eficiente mecanismo de consulta a fontes bibliográficas. Como isso se torna extremamente complexo de ser realizado no próprio "calor da luta" (durante o curso), é aconselhável que os professores contem, de antemão, com uma farta bateria de alternativas já catalogadas e organizadas, prontas para aplicação em sala.

O método de ensino engloba desde as teorias básicas do trabalho pedagógico, até as teorias capitais específicas da disciplina em foco, numa visão completa que traça o encaminhamento das etapas de estruturação do curso. O método expositivo é um exemplo bastante familiar. Mas é preciso que o professor conheça, no mínimo, meia dezena de outras possibilidades alternativas.

A estratégia didática, responsável pela execução das instâncias anteriores (filosofia, relacionamento, metodologia), deve ser, primeiramente, coerente com elas. Isto significa que, ao lado de cada filosofia de trabalho listada como viável, de cada postura de relacionamento com os alunos, de cada método de ensino conhecido, deve estar catalogada uma coletânea de estratégias descritas. Porque a elaboração de uma nova estratégia, na urgência de uma solução rápida durante o transcorrer do curso, além de ser trabalhosa, é arriscada... Deste modo, é importante que exista um "banco de dados" com descrição de várias abordagens de curso, vários tratamentos para os mesmos assuntos teóricos, várias definições de termos principais com várias redes de interligações entre eles, e várias técnicas pedagógicas a serem utilizadas. Caso os problemas diagnosticados exijam a improvisação de uma nova estratégia original, esta deve ser devidamente descrita e equacionada para inclusão na coletânea já existente.

Em resumo, o curso, nestes moldes, se vê obrigado a utilizar a prática da avaliação permanente, seja formal ou informal, porque não se pode deixar para fazer verificações esporádicas ou por amostragens. Cada momento necessita ser bem acompanhado e controlado no seu todo. Então, mesmo que seja o método expositivo o adotado, além das suas usuais avaliações periódicas (as conhecidas "provas" com questões de verificação parcial de conteúdo), torna-se essencial acrescentar avaliações avulsas (rápidas) a todo instante. Neste ponto, valem os conhecidos "teste-surpresa" ou questões diagnósticas, aplicadas no início e/ou no fim de cada aula.

Usualmente, a estratégia didática das disciplinas correspondentes ao campo da Geologia Introdutória é calcada numa abordagem repleta de terminologia técnico-científica; num tratamento de conteúdo em que todas as informações teóricas são esgotadas anteriormente, como preparação indispensável a qualquer ilustração prática, os temas principais sendo colocados todos logo de início como base de fundamentação do conhecimento a ser aprendido e, por fim, as técnicas de ensino girando em torno de apresentações orais corridas e exercícios práticos de fixação de rotinas de procedimento tecnológico. É óbvia sua consonância com o método expositivo. Esta estratégia é largamente consagrada, e, examinada sob o prisma da lógica educacional, é promissora e exeqüível, desde que seja adequada ao perfil da clientela a ser atendida.

No contexto do nosso trabalho, tal estratégia, que chamaremos de "clássica" daqui para frente, infelizmente não tem se mostrado a mais adequada à clientela da disciplina Geologia Introdutória, suscitando distorções e solicitando adaptações necessárias. Eis os motivos:

a) A abordagem acadêmica dificulta a assimilação do conteúdo por alunos que não tiveram nenhuma convivência com temas geológicos em sua história educacional; o assoberbamento exagerado de termos do jargão científico permite confusões e troca de significados das palavras ouvidas em apresentação adensada e ininterrupta; por fim, o que fica é uma memorização de informações soltas constituindo um "aprendizado" nebuloso e sincrético!

b) Quando, após ter recebido todo o cabedal de informações julgadas necessárias, o aluno se vê frente a uma situação prática, ele já não se lembra mais do que ouviu (ou leu), e, mesmo que se lembre, não sabe decidir qual informação deve usar, nem como usar.

c) Os temas principais colocados nas primeiras 
aulas são negligenciados pelos alunos, por não saberem de sua importância, e também pelo fato de que os próprios professores não fazem as devidas retomadas nas aulas seguintes, a não ser em questões de provas escritas (onde os alunos geralmente são mal-sucedidos).

d) Nas apresentações corridas, os alunos são intrinsecamente inseguros, por conta de suas deficiências anteriores, se condiciona a apenas repetir o que ouviram, não raro, sem o menor domínio do significado do que repetem de forma automática.

e) Os exercícios de fixação de conteúdos habituam os alunos (com bagagem teórica deficiente), a "receitas" que julgam válidas em qualquer situação; tendem a seguir automaticamente os mesmos passos de execução que assimilaram, mesmo em contextos em que claramente não se aplicam (são capazes de tentar fazer sorvete com receitas de bacalhau).

Entretanto, nos obrigamos sempre a deixar bem claro que não temos nenhuma aversão à nossa querida estratégia didática clássica (afinal, foi por intermédio dela que nós aprendemos Geologia). Apenas não aceitamos a mesmice de aplicá-la sempre, sem nem sequer imaginar outra alternativa (e existem inúmeras)... Como veremos logo adiante, existem situações em que a estratégia clássica é a melhor opção.

\section{Pré-conceitos ou preconceitos?}

No procedimento usual, uma vez encontrada a "estratégia de ensino", seja de modo consciente ou por reprodução automática, esta é mantida por anos e anos, independente do resultado que venha a ter a cada turma de alunos. Raros professores reformulam seus cursos de uma turma para outra. E praticamente inexistentes são aqueles que reajustam seu procedimento em sala, durante o transcorrer do curso.

$\mathrm{Na}$ verdade, o tão decantado, ou, muitas vezes, o tão criticado "método expositivo", não é o melhor nem o pior. É apenas mais um método, dentre o leque de opções a ser definidas pelo professor. O problema reside no desconhecimento da existência de outros métodos, que não o expositivo.

\section{Riscos associados e seus enfrentamentos}

Alguns poderiam julgar esta proposta de modificar a estratégia didática durante o curso um tanto quanto arriscada, considerando que, ao se promover mudanças constantes na sistemática pedagógica, o aluno poderia vir a tornar-se desorientado e totalmente deslocado dentro do ambiente das aulas. Entretanto, estas mudanças, quando ocorrem, são norteadas por fundamentos metodológicos e pelo retorno ("feed back") proporcionado pelos alunos e devem ser mantidas em funcionamento até que sua avaliação determine o contrário. $\mathrm{O}$ risco de desnorteamento só existiria se as mudanças fossem aleatórias... Depois, o mundo atual apresenta mudanças rápidas e radicais, onde muitas profissões chegam a desaparecer e novas outras surgem. É de interesse especial um curso que combine: um treinamento em se discernir o que acontece ao redor imediato, com uma familiarização em procedimentos adaptativos em situação de mudança. Um estudante habilitado nestes mecanismos irá certamente enfrentar o mercado de trabalho com maior versatilidade. A estrutura do curso, assim, está se propondo flexível a ponto de qualquer mudança, aperfeiçoamento ou reajuste ser promovido imediatamente à constatação de sua necessidade, para, exatamente, preparar o aluno nesta prática tão necessária aos dias de hoje.

\section{Condicionantes da pesquisa em ação}

Desde 1997, vem sendo seguida parcialmente a concepção proposta por uma Comissão Técnica de professores que elaborou o programa da nova disciplina GEO-039 - Geologia Introdutória, mantidas por decisão do Grupo de Trabalho sobre a Matéria Geologia Geral / IGEO, cujas determinações são:

- Filosofia de Trabalho: A nova disciplina deve considerar a Geologia como ciência una, possuindo metodologia própria (o raciocínio geológico), tendo como objeto de estudo toda a Terra e como objetivo desvendar a sua história evolutiva. Dentro deste contexto, devem ser ressaltadas ainda as relações de causa e efeito e a dedução da dinâmica dos processos a partir dos registros geológicos (formas fixadas). A maioria dos processos ocorre em locais inatingíveis e/ ou em velocidades muito lentas em relação à duração da vida humana. Por isso a Geologia 
parte das evidências/formas fixadas/vestígios para deduzir os processos. Cabe lembrar que uma das diretrizes da disciplina é colocar o aluno em contato com o método de trabalho da Geologia. Quando mostramos ao aluno uma rocha alterada, não estamos mostrando o processo de intemperismo, e sim o que resulta dele, as marcas ou vestígios que ele deixa na rocha. Do mesmo modo, quando mostramos uma falésia, não estamos mostrando o processo de erosão, mas sim o que resulta deste processo, os sinais que o evidenciam e nos permitem inferir que um processo erosivo está atuando naquele local. Mas o processo em si é impossível de ser mostrado.

- Relação Professor/Aluno: A participação dos alunos deve ser incentivada seja nas atividades, seja nas decisões (sobre o próprio curso), que devem ser tomadas em conjunto. O professor deve proporcionar situações em que o aluno encontre a solução/resposta por si mesmo, de modo a exercitar a autoconfiança. Claro que as situações propostas e suas soluções devem ser dosadas ao nível da turma.

- Metodologia Básica/Tendência Pedagógica: O método de ensino deve refletir a metodologia da Geologia. Os assuntos devem ser apresentados de forma integrada, para que o aluno desenvolva uma visão una, integrada, da Geologia. As aulas devem enfocar os assuntos sob o prisma do raciocínio geológico. As avaliações devem ser encaradas como instrumento para detectar as deficiências dos alunos, para poder trabalhá-las em seguida. As visitas ao campo durante o semestre são consideradas atividades imprescindíveis.

- Temática do Conteúdo: O conteúdo programático deve atender ao Tema Centralizador, que é a Tectônica Global. Ou seja, todos os assuntos apresentados devem mostrar suas relações com a Tectônica Global. Além disto, deve existir também um Tema Nuclear, o papel da Geologia na Sociedade, de onde devem nascer todas as táticas de motivação do aluno.

- Estrutura do Programa: A estrutura do programa da nova disciplina não poderia ser linear (os assuntos sendo dados separadamente, uns após os outros, como uma linha estendida no chão), uma vez que optou-se por uma visão integrada da Geologia. Decidiu-se que a estrutura do conteúdo programático seria "em blocos”, em número de sete, assim interligados:

a) Conceito de Geologia e evolução do conhecimento geológico;

b) Materiais Terrestres;

c) Tempo Geológico;

d) Sistema Tectônico;

e) Evolução da Paisagem, Recursos Hídricos, Ciclo Hidrológico;

f) Geologia Ambiental e Recursos Naturais;

g) Sistema Solar e Sistema Terra.

- Técnicas Pedagógicas: Não foi feita nenhuma restrição a qualquer técnica pedagógica, dentre todas disponíveis no "arsenal", devendo o professor, no momento da escolha, levar em consideração os objetivos a serem atingidos, as peculiaridades da turma, e as diretrizes indicadas pela estratégia didática vigente.

\section{Considerações adicionais}

É necessário comentar que a aplicação de inovação em sala de aula não deve ser assim a seco, à queima-roupa, sem nenhum cuidado extra. Em primeiro lugar, a depender da inovação, os alunos devem ser consultados se concordam em enfrentar uma situação que irá lhes exigir algo diferente ou além do normal. Depois, toda metodologia, por obrigação de praxe, deve trazer consigo, procedimentos de rotina de reversão dos possíveis efeitos negativos e prevenção de possíveis prejuízos aos alunos. Nosso trabalho conta com:

a) Dispositivos de Segurança;

b) Desapego a técnicas pedagógicas;

c) Acompanhamento de controle.

Nos "Dispositivos de Segurança” constam:

A1) Os alunos têm chance de refazer uma dada avaliação, à sua escolha, exatamente a mesma ou outra equivalente, conforme o caso, até conseguir resultado satisfatório;

A2) Os alunos têm a possibilidade de realizar 
atividades propostas como optativas que podem, ainda a critério do próprio aluno em conjunto com o professor, substituir algumas outras avaliações mal-sucedidas;

A3) São apresentadas "simulações" preventivas de avaliações mais complexas, numa espécie de treinamento em desempenhos mais adequados, e, ainda aqui, o aluno poderá escolher se ficará com a "nota" obtida ou prefere se submeter a avaliação "oficial".

No "Desapego a Técnicas Pedagógicas" partese de um "princípio geral" que seria assim enunciado: "se existem problemas na execução de uma atividade pelos alunos, estes problemas estão localizados na atividade e não nos alunos". Por isso, frente ao insucesso de uma dada técnica aplicada em sala, diferente da atitude usual de insistir com ela até que os alunos forçosamente se enquadrem, pode-se escolher entre as seguintes alternativas:

B1) Adota-se uma outra técnica pedagógica, com base naquilo que se observou na aplicação da anterior;

B2) Faz-se um treinamento mais direto a respeito da atitude fundamental da técnica pedagógica em uso, até que os alunos se apercebam de suas vantagens (ou se mostrem avessos a ela, preferindo outros caminhos);

B3) Subdivide-se a turma em várias equipes, cada qual com a técnica pedagógica que melhor se lhes adapte (esta opção, somente em último caso, pois não é nada fácil "guiar" vários procedimentos ao mesmo tempo).

Nos "Acompanhamentos de Controle", existe uma comparação permanente de cada unidade do curso com as anteriores, e, assim que se perceba um decréscimo no aproveitamento dos alunos, é adotada uma das seguintes medidas:

C1) O assunto em deficiência é novamente retomado em associação (paralela) com as "unidades" seguintes;

C2) O curso dá uma espécie de intervalo rápido, quando se realizam "aulas de revisão";

C3) Recolocam-se situações práticas aos alunos, de modo que revejam, reformulem e aperfeiçoem suas atitudes não adequadas, responsáveis pelo desempenho insatisfatório.
Foram tentadas outras estratégias, como a "do conceito e situação" e da "busca seletiva", mas a mais produtiva foi realmente a "estratégia clássica acadêmica”; que é a que melhor se ajusta à metodologia expositiva.

\section{Referências bibliográficas}

Bulhões P.N.S. s.d. O estudo individualizado: uma experiência com o Método Keller em cursos de graduação na UFRN. < http://www.angrad. org.br/cientifica/artigos/artigos_enangrad/pdfs/ iv_enangrad/O\%20ESTUDO\%20INDIVIDUAL̄IZADO.PDF > . Acesso: junho de 2007.

Cunha M.I.da. 1995. O bom professor e sua prática. 5 ed. Campinas: Papirus.

Moreira M.B. s.d. Sistema personalizado de ensino. $<$ http://www.walden4.com.br/psi/psi_links_port. htm >. Acesso: junho de 2007.

Nérici I.G. 1981. Metodologia do ensino: uma introdução. 2 ed. São Paulo: Atlas. 367p.

Perrenoud P. 1999. Avaliação da excelência à regulação das aprendizagens: entre duas lógicas. Porto Alegre: Artmed.

Ramos G.T. 2001. A questão da mudança na trajetória de educação interdisciplinar. In: Reunião Anual, Associação Nacional de Pós-Graduação e Pesquisa em Educação, 24. Caxambu, out. 2001. < http://www. anped.org.br/24/tp.htm\#gt4>.

UNESCO. 1998. Conferência mundial sobre educação superior. Paris, 1998. Piracicaba: Ed. Unimep.

Villani A., Pacca J.L.A. 1997. Construtivismo, conhecimento científico e habilidade didática no ensino de ciências. São Paulo, Rev. Fac. Educ., 23(1-2), Jan./Dec.

Zabala A. 1999. Os enfoques didáticos. In: Coll C. et al. 1999. O construtivismo na sala de aula. São Paulo: Ática, p.153-195. (Série Fundamentos).

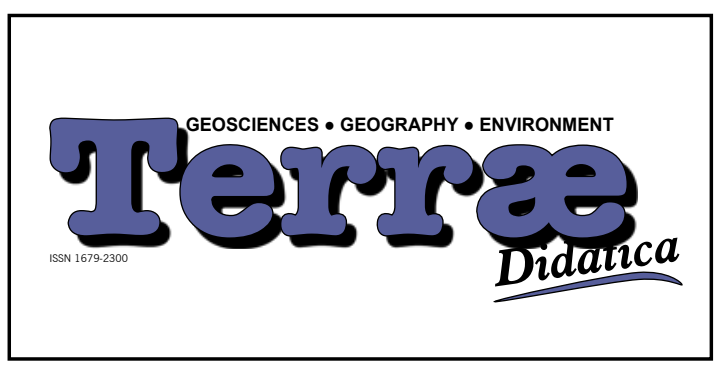

